\title{
Domestic gardens play a dominant role in selecting alien species with adaptive strategies that facilitate naturalization
}

\author{
Wen-Yong Guo ${ }^{1,2}$ (i) Mark van Kleunen ${ }^{3,4}$ (i) Simon Pierce ${ }^{5}$ (i) Wayne Dawson ${ }^{6}$ (1) \\ Franz Essl ${ }^{7}$ (1) Holger Kreft ${ }^{8,9}$ (i) Noëlie Maurel ${ }^{3}$ (I) Jan Pergl ${ }^{1}$ (1) Hanno Seebens ${ }^{10}$ (1) \\ Patrick Weigelt ${ }^{8}$ (D) Petr Pyšek ${ }^{1,11}$ (1)
}

${ }^{1}$ Department of Invasion Ecology, Institute of Botany, The Czech Academy of Sciences, Průhonice, Czech Republic

${ }^{2}$ Department of Bioscience, Aarhus University, Aarhus C, Denmark

${ }^{3}$ Ecology, Department of Biology, University of Konstanz, Konstanz, Germany

${ }^{4}$ Zhejiang Provincial Key Laboratory of Plant Evolutionary Ecology and Conservation, Taizhou University, Taizhou, China

${ }^{5}$ Agroecosystems Ecology and Conservation group, Department of Agricultural and Environmental Sciences (DiSAA), University of Milan, Milan, Italy

${ }^{6}$ Department of Biosciences, Durham University, Durham, United Kingdom

${ }^{7}$ Division of Conservation Biology, Vegetation Biology and Landscape Ecology, University of Vienna, Vienna, Austria

${ }^{8}$ Biodiversity, Macroecology \& Biogeography, University of Goettingen, Göttingen, Germany

${ }^{9}$ Centre of Biodiversity and Sustainable Land Use (CBL), University of Goettingen, Göttingen, Germany

${ }^{10}$ Senckenberg Biodiversity and Climate Research Centre (BiK-F), Frankfurt am Main, Germany

${ }^{11}$ Department of Ecology, Faculty of Science, Charles University, Prague, Czech Republic

\section{Correspondence}

Wen-Yong Guo, Institute of Botany, Department of Invasion Ecology, The Czech Academy of Sciences, CZ-252 43 Průhonice, Czech Republic.

Email: guowyhgy@gmail.com

\begin{abstract}
Aim: Horticulture has been recognized as the main pathway of plant invasions worldwide. The selection of ornamental garden plants is not random, and certain plant characteristics related to adaptive plant strategies are preferred by horticulture and may promote invasion. We examined the direct and indirect interactions between horticultural use, species adaptive strategies (competitive (C), stress-tolerant (S), and ruderal $(\mathrm{R})$ ), native range size and naturalization success.

Location: Global.

Time period: From 1492 to the present.

Major taxa studied: Vascular plants.

Methods: We compiled a dataset of 3,794 plant species including their C-, S- and Rscores, native range size, cultivation in botanic and domestic gardens and whether the species is naturalized in at least one region globally (naturalization incidence). For the 1,711 naturalized species, we also calculated naturalization extent, that is, the number of regions where the species has naturalized. We used phylogenetic path analysis to disentangle the direct and indirect effects of all variables on both naturalization incidence and extent, and the relationships between variables.

Results: Approximately 87 and $94 \%$ of the 1,711 naturalized species were cultivated in botanic or domestic gardens, respectively, compared to c. 55 and $50 \%$ of the 2,083 non-naturalized species, respectively. We found a cascading structure among the examined variables: (a) species exhibiting $\mathrm{C}$ - or $\mathrm{R}$-selected strategies and having large native ranges tended to be cultivated in domestic and botanic gardens, became naturalized outside their native ranges and occupied more regions in their naturalized ranges; (b) C-, S- and R-scores also had indirect effects on naturalization success, which were mediated by horticultural use and native range size; and (c) cultivation in domestic gardens was the strongest factor examined that could explain plant species' naturalization success.
\end{abstract}


Funding information

Austrian Science Fund, Grant/Award Number: I2086-B16; German Research Foundation, Grant/Award Number: 264740629 and SE 1891/2-1; The Czech Academy of Sciences, Grant/Award Number: RVO 67985939 ; Czech Science Foundation, Grant/Award Number: no. 14-36079G Centre of Excellence PLADIAS

\begin{abstract}
Main conclusions: We show that horticulture is not only the major introduction pathway of alien plants, but also that in particular domestic gardens select species predisposed to invade and naturalize.
\end{abstract}

\section{KEYWORDS}

adaptive strategy, horticulture, native range size, naturalization, phylogenetic path analysis, plant invasions, species trait

\section{INTRODUCTION}

Due to intensive globalization, the introduction and establishment of alien species in areas outside their native ranges have increased in recent centuries and still show no sign of decline (Seebens et al., $2017,2018)$. More than 13,000 naturalized alien species of vascular plants have been recorded worldwide (i.e. species that have established self-sustaining populations in new ranges; van Kleunen, Dawson, Essl, et al., 2015; Pyšek et al., 2017). Although many alien plant species have been introduced unintentionally (e.g. as seed contaminants) and have subsequently become naturalized or invasive (i.e. spreading rapidly over large areas and often causing negative environmental or societal impacts; Pyšek, Jarošík, \& Pergl, 2011), a much greater proportion of naturalized plants is introduced intentionally for human uses including ornamental horticulture (DehnenSchmutz, Touza, Perrings, \& Williamson, 2007a; Hulme et al., 2018; Lambdon et al., 2008; Pyšek et al., 2012; Reichard \& White, 2001). Botanic gardens have played a key role in introducing ornamental alien plants and, globally, they hold $>150,000$ plant species in their collections (Hulme, 2011; van Kleunen et al., 2018; Mounce, Smith, \& Brockington, 2017). Thus, although botanic gardens currently play a vital role in conserving plant diversity and preventing extinction (van Kleunen et al., 2018; Mounce et al., 2017; Sharrock, 2011), they also cultivate many species with invasion potential (Hulme, 2011). Similarly, domestic gardens also constitute an important source of potential alien invaders (Dehnen-Schmutz, Touza, Perrings, \& Williamson, 2007b; Hulme, 2015; Hulme et al., 2008, 2018; van Kleunen et al., 2018; Pergl et al., 2016). Indeed, at least 75 and 93\% of the 13,168 naturalized alien plant species are grown in domestic and botanic gardens, respectively (van Kleunen et al., 2018).

The selection of ornamental plants for use in gardens is not random as certain plant traits are desirable for ornamental horticulture (van Kleunen, Johnson, \& Fischer, 2007; Maurel, Hanspach, Kühn, Pyšek, \& van Kleunen, 2016). Traits such as fast growth, ability to grow in disturbed places, early flowering and seeding, production of large numbers of flowers, fruits and/or seeds, lack of seed dormancy and ease of vegetative propagation make species possessing one or more of these attractive, and simple to grow and propagate (Dehnen-Schmutz et al., 2007b; van Kleunen et al., 2018). Some of these biological features, however, are also reported to promote invasion (van Kleunen, Dawson, \& Maurel, 2015; Pyšek \& Richardson, 2007). Moreover, plants selected for horticulture often have relatively large native ranges (Maurel et al., 2016), probably because species with large native ranges are more likely to be collected than species with a restricted native range, and because species with large native ranges may have wider environmental tolerances and thus perform well in gardens with different climates (Moodley, Geerts, Richardson, \& Wilson, 2013). Accordingly, it has been shown that plant invasion success is positively associated with native range size (e.g. Rejmanek \& Richardson, 1996; Dehnen-Schmutz et al., 2007a; Williamson et al., 2009; Pyšek et al., 2015; Razanajatovo et al., 2016). Even though horticulture is recognized as an important source of invasive plants (Hulme, 2011), few studies so far have rigorously examined the direct and indirect relationships between species traits, horticultural use (as garden plants), native range size and naturalization success (van Kleunen et al., 2018; but see Pyšek et al., 2015; Maurel et al., 2016). In addition, differences in the roles of botanic and domestic gardens in plant naturalization success have rarely been tested (van Kleunen et al., 2018).

An alternative approach to analysing a large number of plant functional and life-history traits separately is to focus on one or a few variables that capture most of the variation in plant adaptation. Using two major selection pressures, that is, stress (defined as constraints to growth and productivity by, for example, shortage of resources or suboptimal temperature for metabolism) and disturbance (defined as the removal or destruction of plant biomass by the action of, for example, herbivores, fire or humans), Grime $(1974,1977)$ proposed a niche-based functional classification. Within Grime's scheme, there are three fundamental or primary functional types: (a) competitors (C) exploit conditions of low stress and low disturbance, (b) stress-tolerators (S) are adapted to survive high stress and low disturbance and (c) ruderals (R) exploit conditions of low stress but high disturbance (see also Grime \& Pierce, 2012). While Grime's scheme also included intermediate categories (e.g. CS, CR, RS and (SR), it is a conceptual rather than quantitative scheme. Recently, Pierce et al. (2017) expanded the scope of the CSR concept and proposed a method to calculate quantitative C-, S- and R-scores on the basis of viable combinations of three leaf traits that represent extremes of plant functional specialization (specific leaf area, leaf area and leaf dry matter content) and demonstrated its global applicability. The method of Pierce et al. (2017) also harmonizes Grime's CSR scheme with the well-established worldwide-leaf-economics spectrum (i.e. the trade-off between resource-capture and investment traits; Wright et al., 2004; Onoda et al., 2017) and the plant size gradient that together form the global spectrum of plant form 
and function (Díaz et al., 2016). Recently, Guo et al. (2018) found that plants exhibiting relatively high degrees of $\mathrm{R}$ - and $\mathrm{C}$-selection are positively associated with the likelihood of becoming naturalized, while S-selection is negatively associated. Grime's CSR adaptive strategies [i.e. the C-, S- and R-scores calculated using the Pierce et al. (2017) method] have thus proven useful in contributing towards an explanation of plant naturalization. However, whether CSR adaptive strategies are equally represented among horticultural plants, and how this may in turn affect naturalization success, remains unexplored (Guo et al., 2018). Furthermore, CSR strategies can affect species' native range size, as the different plant characteristics underpinning each strategy, such as seed production, life span, regenerative strategies and frequency of flowering, can determine the potential of species to spread (Grime, 1979).

Several previous studies have addressed the role of biological traits and introduction effort (i.e. using cultivation in gardens as a proxy) in the naturalization of alien species. For instance, DehnenSchmutz et al. (2007b) used regression models to identify biological and socioeconomic predictors of species' abilities to escape from cultivation and become established in Great Britain. However, these authors did not differentiate between direct effects of plant biological traits on naturalization success and indirect effects through different ornamental uses (Dehnen-Schmutz et al., 2007b). To this end, path analysis is a powerful tool (e.g. Hulme, 2011; Pyšek et al., 2015). Using a series of regression and model-fitting analyses, path analysis allows testing a priori hypothesized causal relationships among variables and evaluating direct and indirect relationships between multiple variables simultaneously (Grace, 2006). Maurel et al. (2016) recently used path analysis to evaluate how introduction bias (i.e. the earlier and/or more frequent introduction of species with certain characteristics; van Kleunen, Dawson, \& Maurel, 2015), native range size and biological traits affect the naturalization success of ornamental aliens in Germany. They revealed the direct and indirect effects of native range size, biological traits and planting in botanic gardens on naturalization success. However, Maurel et al. (2016) used only ornamental garden plants, and their measure of planting frequency was based on botanic, not domestic gardens, which precluded separating the contribution of the two.

To assess the relationships between CSR strategy, horticultural use and global naturalization success, we compiled a dataset with estimated C-, S- and R-scores and native range size for 3,794 species of vascular plants. We extracted data from two of the largest online domestic garden-plant databases and from a global botanic garden database, to assess which of these species are used as either domestic or botanic garden plants. Finally, we used the Global Naturalized Alien Flora database (GloNAF; van Kleunen, Dawson, Essl, et al., 2015; Pyšek et al., 2017) to determine which of the species are naturalized and in how many regions outside their native ranges they have naturalized. We then used phylogenetic path analysis, which accounts for the phylogenetic relationships among multiple species (von Hardenberg \& Gonzalez-Voyer, 2013), to disentangle the direct effects of the CSR adaptive strategy and of the native range size on species naturalization success, from their indirect effects mediated by the use of each species in cultivation in either botanic or domestic gardens. We specifically tested the following hypotheses:

1. Cultivation in gardens directly relates to plant naturalization success, and the roles of botanic and domestic gardens in promoting naturalization differ, due to the differences in their occurrence, historical backgrounds, roles in the ornamental nursery supply chain and management measures applied within each type of garden.

2. The representation of C-, S- and R-scores differs between species cultivated in gardens and those that are not (i.e. there is a cultivation bias).

3. Plants with large native ranges tend to be cultivated in both types of garden, and to have a higher chance of naturalizing and to naturalize more widely.

4. The C-, S- and R-scores are directly related to naturalization success, and also have indirect effects via horticultural use and native range size.

\section{METHODS}

\subsection{Species list compilation and calculation of the adaptive strategy scores}

The majority of data on C-, S- and R-scores (for 3,004 species) came from Guo et al. (2018), and were calculated from specific leaf area (SLA), leaf area (LA) and leaf dry matter content (LDMC) data extracted from the TRY database on plant functional traits (Kattge et al., 2011; www.try-db.org) by Pierce et al. (2017). We expanded this dataset by including species from the recently published China Plant Trait Database (Wang et al., 2018), which contains measurements of the three traits (SLA, LA, LDMC) required for calculating C-, S- and R-scores (Wang et al., 2018). Of the 1,215 species in the China Plant Trait Database, 790 were not included in the Guo et al. (2018) CSR dataset. We calculated the C-, S- and R-scores for these 790 species based on the methods and CSR calculator tool 'StrateFy' of Pierce et al. (2017; available at: https://besjournals.onlinelibrary.wiley.com/ doi/abs/10.1111/1365-2435.12722) and combined the two species lists, resulting in a CSR dataset of 3,794 species.

\subsection{Naturalization status and extent}

To determine the naturalization status of the species in the CSR dataset, we compared it with the Global Naturalized Alien Flora database (GloNAF version 1.1, van Kleunen, Dawson, Essl, et al., 2015; Pyšek et al., 2017). This database includes lists of naturalized alien vascular plant species from 864 global mainland and island regions (i.e. countries, states, provinces) covering $83 \%$ of the ice-free land surface, and contains $>13,000$ vascular plant species naturalized in at least one region. For all species from the CSR dataset, we checked whether the species is listed or not as naturalized in at least one 
region in GloNAF (a binary variable that we termed 'naturalization incidence', following Razanajatovo et al., 2016). For the naturalized species, we also extracted the number of GloNAF regions where the species is naturalized as a measure of their global non-native distribution (termed 'naturalization extent'). The final dataset included 1,711 naturalized species and 2,083 non-naturalized species. Among the 1,711 naturalized species, 388 species were short-lived (annual and biennial) herbs, 863 long-lived (perennial) herbs, 210 shrubs and 250 trees. The 2,083 non-naturalized species consisted of 75 shortlived herbs, 874 long-lived herbs, 474 shrubs and 661 trees (Table S1).

\subsection{Garden flora lists}

The exact number of plant species grown as alien species in domestic and botanic gardens is not known (Khoshbakht \& Hammer, 2008). However, to get the most comprehensive lists, we used three large databases to obtain information on which species are cultivated in domestic and botanic gardens worldwide. To compile a global domestic garden flora list, we used Dave's Garden PlantFiles (http:// davesgarden.com/guides/pf/, accessed 23 March 2016), which claims to be the largest online garden-plant encyclopaedia, in combination with the Plant Information Online database (https://plantinfo. umn.edu, accessed 22 November 2017), which is a large database on plants available in North American nurseries. To compile a global botanic garden flora list, we used the PlantSearch database of Botanic Gardens Conservation International (www.bgci.org/plant_search. php, accessed 25 May 2016), which includes species accessions of 1,144 botanic institutions worldwide. In total, we obtained a list of 40,293 species from the Dave's Garden PlantFiles database, a list of 74,781 species from the Plant Information Online database and a list of 162,912 species from the PlantSearch database of Botanic Gardens Conservation International. All species names were standardized via the taxonstand package (Cayuela, Granzow-de la Cerda, Albuquerque, \& Golicher, 2012) in R (version 3.4.3; R Core Team, 2018). We then combined the Plant Information Online species list and the Dave's Garden species list and removed the duplicates, resulting in a domestic garden flora list of 70,108 species. We then checked all species in our CSR dataset to determine whether they are present in, or absent from, the domestic and botanic garden floras. The final botanic garden flora list with CSR data $(2,638)$ consists of 433 short-lived (annual and biennial) herb species, 1,463 longlived (perennial) herbs, 292 shrubs and 450 trees, and the domestic garden flora list with CSR data $(2,659)$ includes 413 short-lived herbs, 1,423 long-lived herbs, 392 shrubs and 431 trees. In both of these lists, the majority of the short-lived herbs and long-lived herbs are naturalized species, while less than half of the shrub and tree species are naturalized (Table S2).

\subsection{Native range size}

For each of the 3,794 species, we quantified native range size as the number of the Taxonomic Database Working Group (TDWG) level-2 regions where a species is native (52 regions in total; Brummitt, 2001). The native range size was compiled using the following online databases: the Germplasm Resources Information Network (GRIN, www.ars-grin.gov/cgi-bin/npgs/html/index.pl), the World Checklist of Selected Plant Families (WCSP, http://apps.kew.org/wcsp/). The Global Biodiversity Information Facility database [GBIF.org (2018), GBIF Home Page. Available from: https://www.gbif.org, accessed March 2018] was also used for some non-naturalized species if no other data were available. We overlaid the GBIF occurrences with the TDWG level-2 borders to derive the estimates of native range size. The native ranges of the 3,794 species are distributed in all continents except Antarctica (TDWG level-1 continent; Table S3). Naturalized species originated from all eight TDWG continents, with Europe and Temperate Asia (the two largest sources of naturalized plants globally; van Kleunen, Dawson, Essl, et al., 2015) being the source of $>1,000$ naturalized species while Australasia and the Pacific Islands contributed $<60$ naturalized species.

\subsection{Phylogeny}

To account for phylogenetic relatedness in the analyses, we constructed a phylogenetic tree of the 3,794 species using the dated supertree of Zanne et al., (2014). The species-level tree was generated with the function S. PhyloMaker (Qian \& Jin, 2016) in R. This function first prunes the supertree, and then inserts species that are absent from the supertree into their families or genera in the tree using the approach implemented in Phylomatic and Bladj (Webb, Ackerly, \& Kembel, 2008).

\subsection{Statistical analysis}

All analyses were carried out in R 3.4.3 (R Core Team, 2018). The C-, $\mathrm{S}$ - and R-scores were standardized to a mean of zero and a standard deviation of one to facilitate comparisons between models (Schielzeth, 2010). The variables of native range size and naturalization extent were $\log _{10}$-transformed to normalize the data.

A size proportional Venn diagram was used to show the overlaps among the 3,794 species with CSR data that have become naturalized, the species that are cultivated in botanic gardens and those that are cultivated in domestic gardens via the Vennerable package (Swinton, 2009). To test whether the proportion of naturalized species differed between the groups of species cultivated in gardens and those not known to be cultivated in gardens (separately for botanic gardens and domestic gardens), we used a chi-square test of independence.

Triangular plots were made to visualize the C-, S- and R-scores of the species present in or absent from each garden flora list using the ggtern package (Hamilton, 2015). We further ran phylogenetic linear models for each score with the presence in or absence from each garden flora as the fixed factor using the phylolm package (Ho \& Ane, 2014). To examine whether the C-, S- and R-scores differed among species classes (e.g. present in versus absent from garden flora lists), we defined the following groupings: (a) species absent 
from both garden flora lists, (b) present in the botanic garden flora list but absent from the domestic garden flora list, (c) present in the domestic garden flora list but absent from the botanic garden flora list and (d) present in both garden flora lists. We ran phylogenetic linear models for each score with the new four-level group as the fixed factor. The estimated means and the standard errors (SES) were back-transformed to the original scales for ease of interpretation.

Phylogenetic path analyses were used to test, for each of the C-, S- and R-scores separately, (a) the direct effects of the respective C-, $\mathrm{S}$ - and R-scores, native range size, cultivation in botanic gardens, and cultivation in domestic gardens on naturalization incidence; (b) the effects of the C-, S- and R-scores and native range size on presence in botanic and domestic gardens; and (c) the effect of the C-, S- and R-scores on native range size. We ran the same models for naturalization extent using naturalized species only. Phylogenetic path analysis was carried out in the R package phylopath using the default settings, that is, logistic_Maximum Penalized Likelihood Estimation (MPLE) estimation method for the naturalization incidence models, and Pagel's lambda model for the naturalization extent models (van der Bijl, 2018). For each model, we also ran several candidate models, and ranked all candidate models according to their C-statistic information criterion $(\mathrm{ClCc})$, with $\Delta \mathrm{ClC} c \leq 2$ as the best-supported model (von Hardenberg \& Gonzalez-Voyer, 2013). The strength of the indirect paths was calculated by multiplying the path coefficients along them.

\section{RESULTS}

\subsection{Cultivation bias}

In our dataset of species with CSR data, the botanic garden and domestic garden floras together shared $58.3 \%$ of the species $(2,213$ out of 3,794 species), with the two garden types containing $84 \%$ $(2,638)$ and $83 \%(2,659)$ of the species, respectively (Figure $1 \mathrm{a})$. A total of 1,711 species were naturalized outside their native range, and of these, $88 \%(1,499)$ and $94 \%(1,614)$ were listed in botanic and domestic gardens, respectively. Among the 2,083 non-naturalized species, only $55 \%(1,139)$ and $50 \%(1,045)$ were listed in botanic and domestic gardens, respectively. Species cultivated in any type of garden were significantly more likely to become naturalized than those not grown in gardens $\left(\chi^{2}=479.2\right.$ and 871.7 for domestic and botanic gardens, respectively, d.f. $=1, p<.001$; Figure 1b, c).

\subsection{Adaptive strategies of garden and non- garden plants}

Species present in and absent from both garden floras occupied divergent spaces in the triangular CSR scheme (i.e. shifted means and corresponding confidence intervals (Cls); Figure 2). Species with either low $\mathrm{S}$-scores or high R-scores tended to occur in gardens, regardless of whether or not the species phylogeny was accounted for (Figure 2, Table S4). After accounting for species relatedness, species cultivated in botanic gardens tended to have higher C-scores than those absent from botanic gardens, while species cultivated in domestic gardens showed similar C-scores to those absent from domestic gardens (Table S4).

When considering occurrence in botanic and domestic gardens jointly, species present in both types of gardens had significantly lower S-scores than those present in only one type of garden, and those absent from both types of gardens had the highest S-scores (Fig. S1). Species present in only domestic or in both types of gardens had significantly higher R-scores than the other two classes (Fig. S1). Furthermore, species only present in botanic gardens showed the highest C-scores, followed by species present in both types of gardens, and species absent from both types of gardens or present only in domestic gardens had the lowest C-scores. (Fig. S1).

\subsection{Naturalization incidence}

Separate path analyses of each of the C-, S- and R-scores showed that naturalization incidence was positively and directly related to $\mathrm{C}$ - and R-scores, and negatively to the S-score (Figure 3a-c). Native range size also had a direct positive effect on naturalization incidence. Cultivation in domestic and botanic gardens had significantly positive effects on naturalization incidence. This direct effect was much stronger for domestic than for botanic gardens, and it was stronger than the effects of $\mathrm{C}$ - and $\mathrm{R}$-scores, and of native range size. However, as native range size also had positive effects on cultivation in domestic and botanic gardens, it also affected naturalization incidence indirectly. Similarly, C-, S- and R-scores had indirect effects on naturalization incidence. This was because the C- and R-scores were positively and the S-score was negatively related to cultivation in the two garden types (Figure $3 a-c$ ), and because the R-score was positively and the $\mathrm{S}$-score negatively related to native range size (Figure 3b, c).

\subsection{Naturalization extent}

The analysis of naturalization extent among the 1,711 naturalized species revealed a similar overall pattern as the analysis of naturalization incidence (Figure $3 a-c$ cf. Figure $3 d-f$ ). Naturalization extent was positively related to $\mathrm{C}$ - and $\mathrm{R}$-scores, and negatively to the $\mathrm{S}$-score, and native range size had a positive effect on naturalization extent (Figure 3d-f). Cultivation in domestic and botanic gardens had significant positive effects on naturalization extent, and this effect was again much stronger for domestic than for botanic gardens (Figure 3d-f). Moreover, it was stronger than the effects of the C- and R-scores, and of native range size (Figure $3 d-f$ ). Native range size also had a positive effect on cultivation in the two types of gardens; thus, it also indirectly affected naturalization extent. Likewise, the C-, S- and R-scores had indirect effects on naturalization extent. The C-score was positively related to 


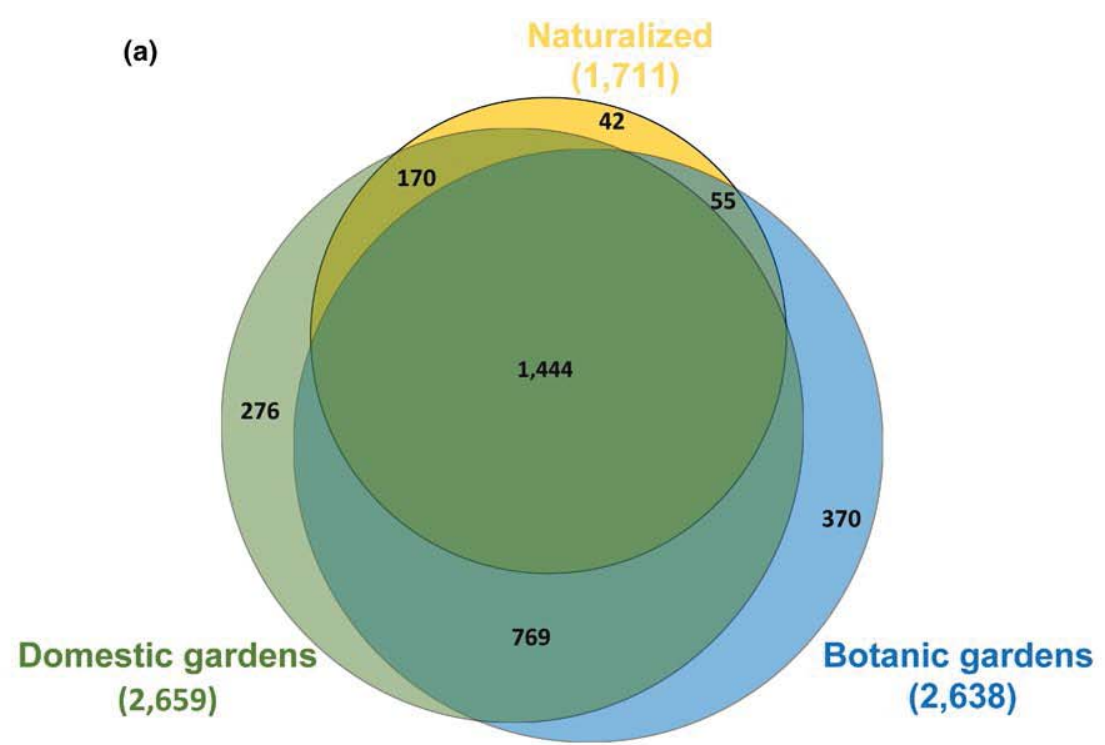

(b) Listed as cultivated in domestic gardens

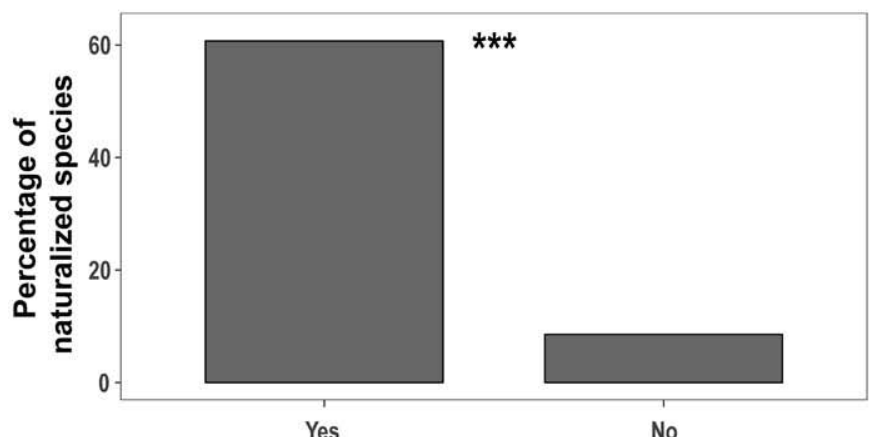

(c) Listed as cultivated in botanic gardens

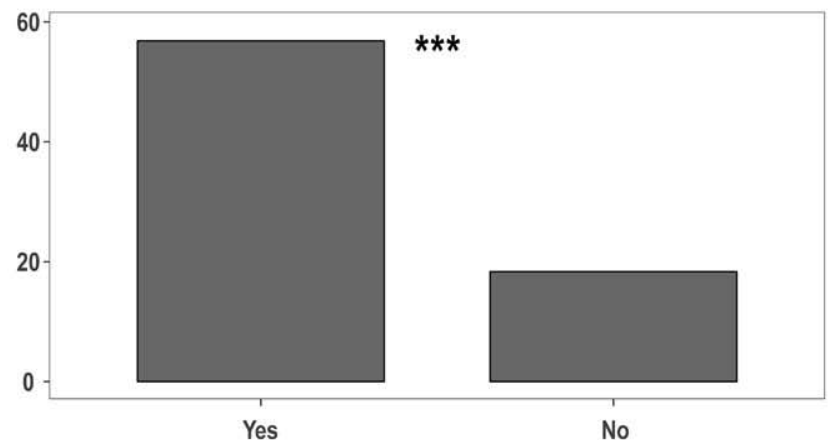

FIGURE 1 (a) Size-proportional Venn diagram showing the overlaps between the botanic $(2,638)$ and domestic $(2,659)$ garden flora lists, and naturalized (1,711) species of the final dataset (3,794 species). Of the 2,083 non-naturalized species, 672 are not listed as cultivated in either type of garden. (b, c) Bar plots of the observed percentage of each group that is naturalized, and the significance level of the corresponding chi-square test of independence, ${ }^{* * *} p<.001\left[\chi^{2}=871.7\right.$ and 479.2 for (b) and (c), respectively; d.f. = 1$]$. "Yes" indicates species present in the garden flora list; "No" indicates species absent from the garden flora list [Colour figure can be viewed at wileyonlinelibrary. com]

cultivation in both types of garden (Figure 3d). In contrast, the $\mathrm{S}$-score was only negatively related to cultivation in botanic gardens (Figure 3e), and conversely, the R-score was only positively related to cultivation in botanic gardens (Figure $3 f$ ). So, for the subset of naturalized species, neither the S-score nor the R-score were significantly related to cultivation in domestic gardens. In addition, the $\mathrm{C}$-score and the $\mathrm{S}$-score were negatively related to native range size, while the $\mathrm{R}$-score was positively related to native range size (Figure $3 d-f$ ).

\section{DISCUSSION}

Combining four global datasets and using phylogenetic path analysis, we demonstrate that there are direct impacts of cultivation in different types of garden, as well as of CSR strategies and native range size on the naturalization success of plant species. This holds true for both naturalization incidence, that is, whether the species is capable of establishing in a new region following introduction, and for naturalization extent, a measure of how widely naturalized it has become across the globe. Species cultivated in domestic and botanic gardens, exhibiting a high degree of C- or R-selection and occupying a large native range tend to become naturalized outside their native range and occupy larger naturalized ranges. Importantly, we showed that there is a cultivation bias, as species with high degrees of C- and $\mathrm{R}$-selection and a low degree of $\mathrm{S}$-selection are disproportionally more likely to be cultivated in gardens. We further revealed that species exhibiting greater $\mathrm{R}$-selection tended to have large native ranges compared to species with mostly $\mathrm{C}$ - and $\mathrm{S}$-selected strategies. This shows that C-, S- and R-scores have both direct and indirect effects - mediated by cultivation bias and effects on native range size - on naturalization success. Finally, we demonstrate that cultivation in domestic gardens is more strongly associated with plant species' naturalization success than any other factors studied here.

While globally c. $4 \%$ of the vascular plant species have become naturalized somewhere (van Kleunen, Dawson, Essl, et al., 2015; 
(a) Botanic gardens $100 \quad \rightarrow$ Absent

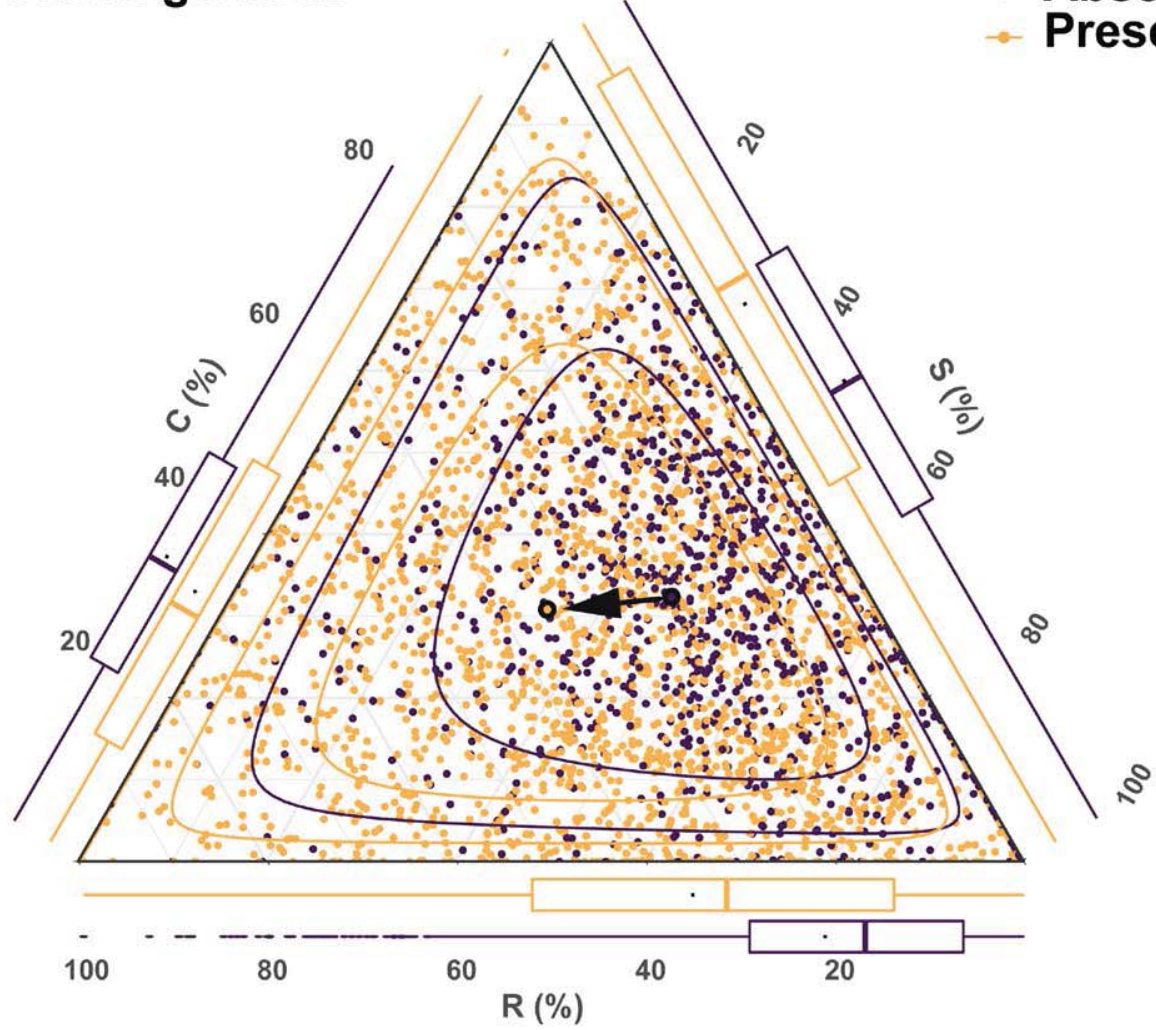

(b) Domestic gardens

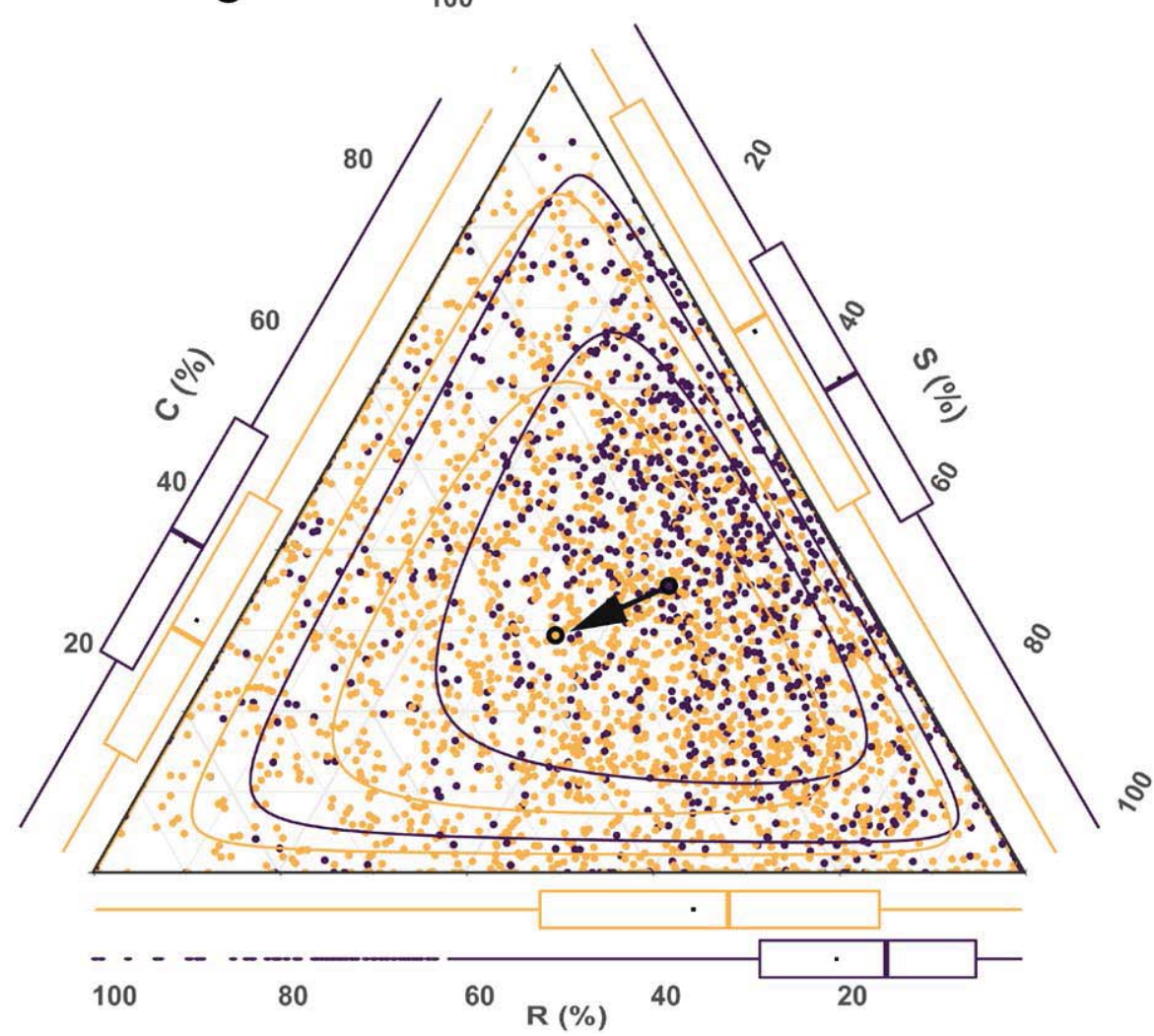

FIGURE 2 Occurrences of the 3,794 species within the competitive, stress-tolerant, and ruderal (CSR) adaptive strategy triangle: (a) botanic gardens; (b) domestic gardens. "Absent" indicates species not occurring in the garden flora list; "Present" indicates species occurring in the garden flora list. The triangles from interior to outward are 50 and $90 \%$ confidence regions, respectively, calculated using the Mahalanobis distance (Hamilton, 2015). The black arrows indicate the shift of means from species absent from the garden flora list to species present in the garden flora list. Along each axis of the ternary plot, a boxplot of the respective strategy score displays the median (line in the middle of boxes), the mean (black dot), the interquartile range (boxes), \pm 1.5 times the interquartile range (whiskers) and outliers (dots) for each group of species [Colour figure can be viewed at wileyonlinelibrary.com] 
Naturalization incidence

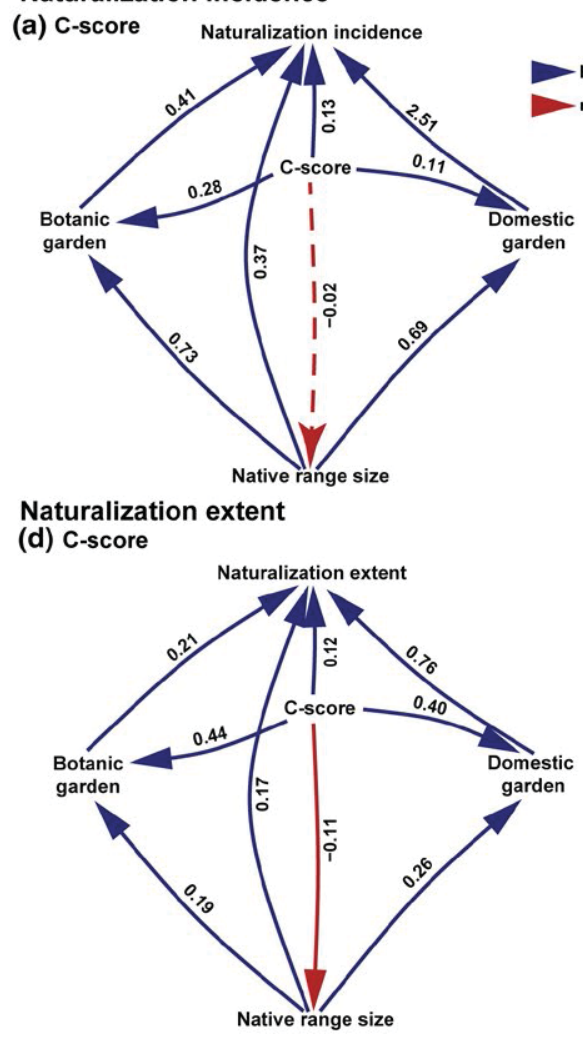

(b) S-score Naturalization incidence

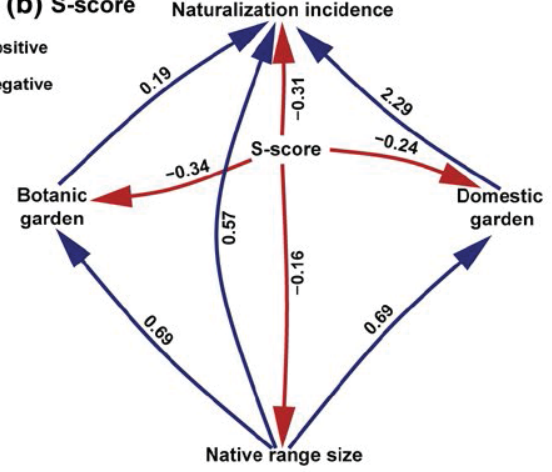

(e) S-score

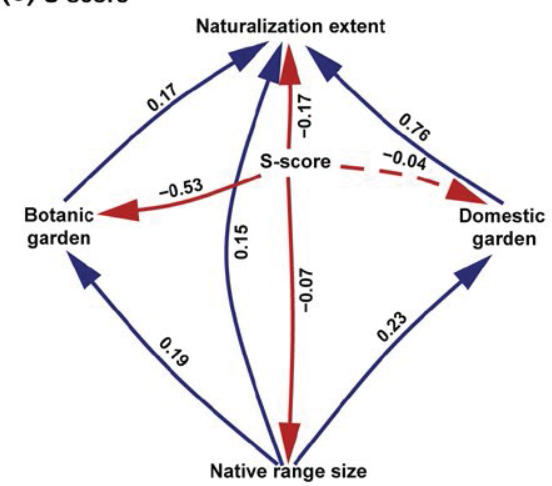

(c) R-score

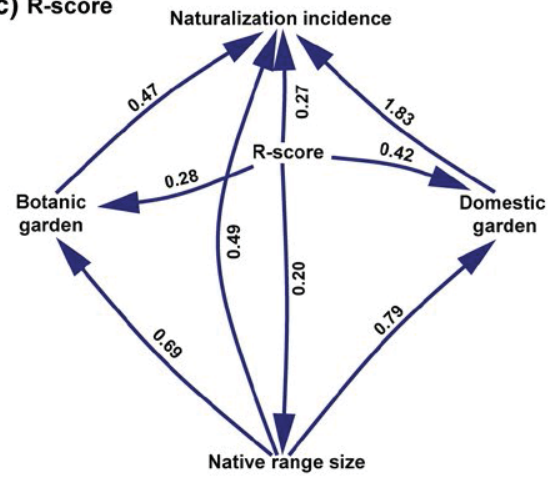

(f) R-score

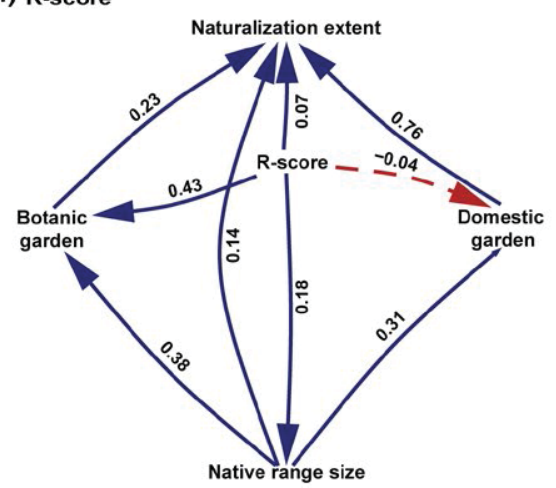

FIGURE 3 Phylogenetic path analyses assessing the relationships between naturalization incidence (a-c) and naturalization extent (d-f) on competitor- (C-; a, d), stress-tolerator- (S-; b, e) and ruderal- (R-; C, f) scores, native range size [no. of Taxonomic Database Working Group (TDWG) level-2 regions], whether or not the species is listed in botanic gardens and in domestic gardens (Botanic garden and Domestic garden). Red lines indicate negative relationships, and blue lines indicate positive relationships. Numbers aside the lines are standardized regression coefficients. Solid lines indicate significant relationships [95\% confidence intervals (Cls) exclude zero], and dashed lines indicate non-significant relationships ( $95 \% \mathrm{Cls}$ include zero) [Colour figure can be viewed at wileyonlinelibrary.com]

van Kleunen et al., 2018), $45 \%$ of the species in our study are naturalized. Similarly, while globally c. 48 and $21 \%$ of the vascular plants are estimated to be cultivated in botanic and domestic gardens, respectively (van Kleunen et al., 2018), the corresponding percentages in our dataset were 84 and $83 \%$. In other words, the species included in our study were not a random selection of the global flora as naturalized and cultivated species were overrepresented. This most likely reflects that such species are usually more common and intensively studied, and hence better represented in trait databases. This nonrandom representation of species in our dataset, however, should not bias the results as long as there is no bias with regard to the inclusion of species with different CSR strategies among naturalized and non-naturalized species, and among cultivated and non-cultivated species.

The role of ornamental gardens as the dominant pathway of plant invasions has long been acknowledged (Hulme, 2011; Hulme et al., 2018; van Kleunen et al., 2018; Lambdon et al., 2008; Mack, 2000), and studies have pointed to botanic gardens as potential sources of invasive plants (Hulme, 2011). It was recently shown that of the global naturalized alien flora, a larger proportion is known to be grown in botanic than in domestic gardens (van Kleunen et al., 2018). However, in our dataset, domestic gardens hosted more of the naturalized alien species than botanic gardens (Figure 1a). Moreover, the effect of cultivation in domestic gardens on the naturalization success of alien plants was much stronger than that of cultivation in botanic gardens (Figure 3), indicating that alien species grown in domestic gardens represent a greater risk of escaping and becoming naturalized. Although this is not unexpected given that the area covered by domestic gardens is several orders of magnitude greater than that occupied by botanic gardens, this has not been shown before using a large set of plant species worldwide.

As we do not have information on the dates of introduction of species to regions outside their native range in our study, we cannot exclude the possibility that botanic gardens had a stronger effect on naturalization success of alien species in the past. This seems plausible particularly during the 19 th and early 20 th centuries, when many alien species were first introduced into botanic gardens before entering the ornamental nursery supply chain and being planted in domestic gardens (Drew, Anderson, \& Andow, 2010; van Kleunen et al., 2018; Sharrock, 2011). Currently, many botanic gardens fulfill education and conservation missions via scientific expertise, and some apply strict regulations for inclusion of species in their collections and maintain species for extended periods to monitor their potential 
for escape and establishment (Sharrock, 2011). For the nursery industry, the main supplier of plants for domestic gardens, there are some voluntary codes of conduct, but their effectiveness is unclear. Moreover, with the increase in e-commerce, plants, including many potentially or known invasive species, can be bought from almost any place on Earth (Humair, Humair, Kuhn, \& Kueffer, 2015). The management of domestic gardens is rarely regulated and depends largely on an individual owner's experience and interests (Loram, Warren, Thompson, \& Gaston, 2011; Robinson, Inger, \& Gaston, 2017; but see a recent study on identifying potential invasive plants based on gardeners' knowledge in Great Britain; Dehnen-Schmutz \& Conroy, 2018). Compared to alien species introduced through other pathways, species cultivated in ornamental gardens are usually introduced and become naturalized earlier (van Kleunen et al., 2018; Pyšek, Sádlo, Mandák, \& Jarošík, 2003). Thus, long residence times and high propagule pressure achieved through planting in numerous gardens over wide geographical expanses, likely underpin the greater naturalization extent of ornamental garden plants (Pyšek et al., 2015).

In a previous study, plants with particular adaptive strategies (in terms of C-, S- and R-scores) were shown to differ in their naturalization likelihood, with competitors and ruderals more likely to become naturalized than stress-tolerators (Guo et al., 2018). However, whether this was because of differences in the intrinsic capacity of C-, S- and R-selected species to establish in new regions, or mediated through other factors such as introduction effort, remained unclear. In this follow-up study, by considering horticultural use as a proxy for introduction effort and using phylogenetic path analysis, we disentangled the direct and indirect effects of plant adaptive strategies on naturalization success. We found relationships between C-, S- and R-scores and naturalization success consistent with previous findings by Guo et al. (2018), which indicates that these relationships are not merely due to the differences in species' cultivation in gardens. In addition, however, our results revealed that the selection of plants for horticultural use is not random. Species with a stress-tolerant strategy were less likely to be used as garden plants, and those with prevailing competitor or ruderal strategies had a much higher chance of being used. The typical characteristics of competitor and ruderal species, for example, rapid growth and establishment, high flowering frequency and high phenotypic plasticity (Grime, 1979, 1988), not only make these species easy to cultivate, but are also likely to be desired by gardeners (van Kleunen et al., 2018). On the other hand, the stress-tolerators are hardy, but grow slowly and need a long time to germinate and flower; attributes that make them less desirable for use in the mesic, high nutrient conditions often found in gardens.

Our results corroborate previous findings that a large native range is positively associated with naturalization likelihood, that is, naturalization incidence (van Kleunen et al., 2007; Razanajatovo et al., 2016), and the number of regions where naturalized, that is, naturalization extent (Pyšek et al., 2015). Species with a large native range are more likely to be adapted to a wide range of environmental conditions than those with a restricted native distribution, and this would increase the chances that widespread species will be preadapted to the environment in the introduced range (Pyšek et al., 2009, 2015). In addition, species might have a large native range because they have a high dispersal ability (Gaston, 2003), which might also promote naturalization success (Bucharova \& van Kleunen, 2009; Herron, Martine, Latimer, \& Leicht-Young, 2007). A large native range also makes a species more likely to be selected as a garden plant, both for botanic and domestic gardens (Figure 3), probably because species with large native distributions are more likely to be encountered by plant collectors (van Kleunen et al., 2007; Pyšek et al., 2009). Furthermore, the different plant adaptive strategies were also related in different ways to the native range size. Ruderals tended to have larger native ranges, while competitors and stress-tolerators tended to have smaller native ranges. The larger native ranges of ruderals could be related to large quantities of seed produced each year and efficient seed dispersal over relatively large distances, usually by wind, whereas the other strategies usually allocate fewer resources to seed (Grime, 1979, 1988).

Importantly, while our study revealed significant direct effects of CSR strategies, cultivation in botanic and domestic gardens, and native range size on naturalization success, we also identified many indirect paths. Each C-, S- and R-score can influence naturalization incidence or extent via five indirect paths: (a) via botanic garden presence, (b) via domestic garden presence, (c) via native range size, (d) via native range size and presence in domestic gardens and (e) via native range size and presence in botanic gardens (Table S5). Overall, the combined effects of the first four indirect paths of the C-, Sand R-scores were much bigger than those of the corresponding direct paths, especially in naturalization incidence models (Table S5). Similarly, the indirect effects of native range size on naturalization success were larger than the direct effect (Table S5). In particular, the indirect effects of paths that involved domestic gardens were large (Table S5) due to the overwhelming effect of cultivation in domestic gardens on plant naturalization success. These findings emphasize the importance of considering introduction or cultivation bias when testing effects of species characteristics on naturalization success.

In our study, we tested the relationships between explanatory variables and the likelihood of naturalization and its extent, using the Global Naturalized Alien Flora database. Even though we could speculate that similar traits that favour naturalization would also lead to easier transition to the invasive stage, based on previous studies (e.g. Pyšek et al., 2003; Pyšek et al., 2009; Pyšek et al., 2011; Dehnen-Schmutz et al., 2007b; Pyšek \& Richardson, 2007), we refrain from doing so here. The reason is that the data on invasive species are available for only a subset of the world regions and suffer from greater variation due to differing criteria that individual authors apply to define invasive taxa (e.g. species that spread rapidly, species with negative impacts or species growing in natural habitats; Pyšek et al., 2017). Further detailed studies focusing on the invasion stage are, therefore, needed to test these relationships if data permit. 
To the best of our knowledge, this is the first study to disentangle the hierarchical relationships among CSR strategies, native range size, horticultural use and naturalization success. Phylogenetic path analysis enabled us to identify the cascading structures among these variables. From this suite of variables, we identified the strongest factors driving naturalization success, that is, presence in domestic gardens, large native range size and competitor and ruderal adaptive strategies. In particular, we showed that cultivation of a plant species in domestic gardens had a much stronger influence on naturalization than cultivation in botanic gardens. Domestic gardens generate high propagule pressures, and select species that are more likely to naturalize (i.e. species with $\mathrm{C}$ - and $\mathrm{R}$-strategies and large native range).

\section{ACKNOWLEDGMENTS}

PP and JP were supported by project no. 14-36079G Centre of Excellence PLADIAS (Czech Science Foundation) and long-term research development project RVO 67985939 (The Czech Academy of Sciences). FE acknowledges funding from the Austrian Science Fund (FWF, grant 12086-B16). HS acknowledges support from the German Research Foundation (DFG, grant SE 1891/2-1). MvK acknowledges funding from the German Research Foundation (DFG, project number 264740629).

\section{ORCID}

Wen-Yong Guo (iD https://orcid.org/0000-0002-4737-2042

Mark van Kleunen (iD https://orcid.org/0000-0002-2861-3701

Simon Pierce (D) https://orcid.org/0000-0003-1182-987X

Wayne Dawson iD https://orcid.org/0000-0003-3402-0774

Franz Essl (D) https://orcid.org/0000-0001-8253-2112

Holger Kreft (iD) https://orcid.org/0000-0003-4471-8236

Noëlie Maurel (D) https://orcid.org/0000-0002-7039-1794

Jan Pergl (iD https://orcid.org/0000-0002-0045-1974

Hanno Seebens (iD https://orcid.org/0000-0001-8993-6419

Patrick Weigelt iD https://orcid.org/0000-0002-2485-3708

Petr Pyšek (DD https://orcid.org/0000-0001-8500-442X

\section{REFERENCES}

Brummitt, R. K. (2001). World geographical scheme for recording plant distributions: Edition 2. Published for International Working Group on Taxonomic Databases for Plant Sciences (TDWG). Hunt Institute for Botanical Documentation \& Carnegie Mellon University, Pittsburgh.
Bucharova, A., \& van Kleunen, M. (2009). Introduction history and species characteristics partly explain naturalization success of North American woody species in Europe. Journal of Ecology, 97, 230-238. https://doi.org/10.1111/j.1365-2745.2008.01469.x

Cayuela, L., Granzow-de la Cerda, Í., Albuquerque, F. S., \& Golicher, D. J. (2012). taxonstand: An R package for species names standardisation in vegetation databases. Methods in Ecology and Evolution, 3, 10781083. https://doi.org/10.1111/j.2041-210X.2012.00232.x

Dehnen-Schmutz, K., \& Conroy, J. (2018). Working with gardeners to identify potential invasive ornamental garden plants: Testing a citizen science approach. Biological Invasions, 20, 3069-3077. https:// doi.org/10.1007/s10530-018-1759-3

Dehnen-Schmutz, K., Touza, J., Perrings, C., \& Williamson, M. (2007a). A century of the ornamental plant trade and its impact on invasion success. Diversity and Distributions, 13, 527-534. https://doi. org/10.1111/j.1472-4642.2007.00359.x

Dehnen-Schmutz, K., Touza, J., Perrings, C., \& Williamson, M. (2007b). The horticultural trade and ornamental plant invasions in Britain. Conservation Biology, 21, 224-231. https://doi. org/10.1111/j.1523-1739.2006.00538.x

Díaz, S., Kattge, J., Cornelissen, J. H. C., Wright, I. J., Lavorel, S., Dray, S., ... Gorné, L. D. (2016). The global spectrum of plant form and function. Nature, 529, 167-171. https://doi.org/10.1038/nature16489

Drew, J., Anderson, N., \& Andow, D. (2010). Conundrums of a complex vector for invasive species control: A detailed examination of the horticultural industry. Biological Invasions, 12, 2837-2851. https:// doi.org/10.1007/s10530-010-9689-8

Gaston, K. J. (2003). The structure and dynamics of geographic ranges. UK: Oxford University Press.

Grace, J. B. (2006). Structural equation modeling and natural systems. Cambridge, UK: Cambridge University Press.

Grime, J. P. (1974). Vegetation classification by reference to strategies. Nature, 250, 26-31. https://doi.org/10.1038/250026a0

Grime, J. P. (1977). Evidence for existence of three primary strategies in plants and its relevance to ecological and evolutionary theory. The American Naturalist, 111, 1169-1194. https://doi.org/10.1086/283244

Grime, J. P. (1979). Plant strategies and vegetation processes. Chichester, UK: Wiley.

Grime, J. P. (1988). The C-S-R model of primary plant strategies - origins, implications and tests. In E. D. Gottlieb \& S. K. Jain (Eds.), Plant evolutionary biology (pp. 371-393). London, UK: Chapman and Hall.

Grime, J. P., \& Pierce, S. (2012). The evolutionary strategies that shape ecosystems. Chichester, UK: Wiley-Blackwell.

Guo, W.-Y., van Kleunen, M., Winter, M., Weigelt, P., Stein, A., Pierce, S., ... Pyšek, P. (2018). The role of adaptive strategies in plant naturalization. Ecology Letters, 21, 1380-1389. https://doi.org/10.1111/ ele.13104

Hamilton, N. (2015). ggtern: An extension to 'ggplot2', for the creation of ternary diagrams. $R$ package version 1.0.6.0. Retrieved from http:// www.ggtern.com/

Herron, P. M., Martine, C. T., Latimer, A. M., \& Leicht-Young, S. A. (2007). Invasive plants and their ecological strategies: Prediction and explanation of woody plant invasion in New England. Diversity and Distributions, 13, 633-644. https://doi.org/10.1111/j.1472-4642.2007.00381.x

Ho, L. S. T., \& Ane, C. (2014). Package "Phylolm" - Phylogenetic linear regression. Retrieved from https://cran.r-project.org/web/packages/ phylolm/index.html

Hulme, P. E. (2011). Addressing the threat to biodiversity from botanic gardens. Trends in Ecology and Evolution, 26, 168-174. https://doi. org/10.1016/j.tree.2011.01.005

Hulme, P. E. (2015). Resolving whether botanic gardens are on the road to conservation or a pathway for plant invasions. Conservation Biology, 29, 816-824. https://doi.org/10.1111/cobi.12426

Hulme, P. E., Bacher, S., Kenis, M., Klotz, S., Kühn, I., Minchin, D., ... Vilà, M. (2008). Grasping at the routes of biological invasions: A framework for integrating pathways into policy. Journal of Applied Ecology, 45, 403-414. https://doi.org/10.1111/j.1365-2664.2007.01442.x 
Hulme, P. E., Brundu, G., Carboni, M., Dehnen-Schmutz, K., Dullinger, S., Early, R., ... Verbrugge, L. N. H. (2018). Integrating invasive species policies across ornamental horticulture supply chains to prevent plant invasions. Journal of Applied Ecology, 55, 92-98. https://doi. org/10.1111/1365-2664.12953

Humair, F., Humair, L., Kuhn, F., \& Kueffer, C. (2015). E-commerce trade in invasive plants. Conservation Biology, 29, 1658-1665. https://doi. org/10.1111/cobi.12579

Kattge, J., Díaz, S., Lavorel, S., Prentice, I. C., Leadley, P., Bönisch, G., ... Wirth, C. (2011). TRY - A global database of plant traits. Global Change Biology, 17, 2905-2935. https://doi. org/10.1111/j.1365-2486.2011.02451.x

Khoshbakht, K., \& Hammer, K. (2008). How many plant species are cultivated? Genetic Resources and Crop Evolution, 55, 925-928. https:// doi.org/10.1007/s10722-008-9368-0

Lambdon, P. W., Pyšek, P., Basnou, C., Hejda, M., Arianoutsou, M., Essl, F., ... Hulme, P. E. (2008). Alien flora of Europe: Species diversity, temporal trends, geographical patterns and research needs. Preslia, 80, 101-149.

Loram, A., Warren, P., Thompson, K., \& Gaston, K. (2011). Urban domestic gardens: The effects of human interventions on garden composition. Environmental Management, 48, 808-824. https://doi.org/10.1007/ s00267-011-9723-3

Mack, R. N. (2000). Cultivation fosters plant naturalization by reducing environmental stochasticity. Biological Invasions, 2, 111-122. https:// doi.org/10.1023/A:1010088422771

Maurel, N., Hanspach, J., Kühn, I., Pyšek, P., \& van Kleunen, M. (2016). Introduction bias affects relationships between the characteristics of ornamental alien plants and their naturalization success. Global Ecology and Biogeography, 25, 1500-1509. https://doi.org/10.1111/ geb. 12520

Moodley, D., Geerts, S., Richardson, D. M., \& Wilson, J. R. U. (2013). Different traits determine introduction, naturalization and invasion success in woody plants: Proteaceae as a test case. PLOS ONE, 8, e75078. https://doi.org/10.1371/journal.pone.0075078

Mounce, R., Smith, P., \& Brockington, S. (2017). Ex situ conservation of plant diversity in the world's botanic gardens. Nature Plants, 3, 795802. https://doi.org/10.1038/s41477-017-0019-3

Onoda, Y., Wright, I. J., Evans, J. R., Hikosaka, K., Kitajima, K., Niinemets, Ü., ... Westoby, M. (2017). Physiological and structural tradeoffs underlying the leaf economics spectrum. New Phytologist, 214, 14471463. https://doi.org/10.1111/nph.14496

Pergl, J., Sádlo, J., Petřík, P., Danihelka, J., Chrtek, J., Hejda, M., ... Pyšek, P. (2016). Dark side of the fence: Ornamental plants as a source of wild-growing flora in the Czech Republic. Preslia, 88, 163-184.

Pierce, S., Negreiros, D., Cerabolini, B. E. L., Kattge, J., Díaz, S., Kleyer, M., ... Tampucci, D. (2017). A global method for calculating plant CSR ecological strategies applied across biomes world-wide. Functional Ecology, 31, 444-457. https://doi.org/10.1111/1365-2435.12722

Pyšek, P., Jarošík, V., \& Pergl, J. (2011). Alien plants introduced by different pathways differ in invasion success: Unintentional introductions as a threat to natural areas. PLoS ONE, 6, e24890. https://doi. org/10.1371/journal.pone.0024890

Pyšek, P., \& Richardson, D. M. (2007). Traits associated with invasiveness in alien plants: Where do we stand? In W. Nentwig (Ed.), Biological invasions (pp. 97-125). Berlin, Germany: Springer-Verlag. https://doi. org/10.1007/978-3-540-36920-2_7

Pyšek, P., Sádlo, J., Mandák, B., \& Jarošík, V. (2003). Czech alien flora and the historical pattern of its formation: What came first to Central Europe? Oecologia, 135, 122-130. https://doi.org/10.1007/ s00442-002-1170-7

Pyšek, P., Danihelka, J., Sádlo, J., Chrtek, J., Chytrý, M., Jarošík, V., ... Tichý, L. (2012). Catalogue of alien plants of the Czech Republic (2nd edition): Checklist update, taxonomic diversity and invasion patterns. Preslia, 84, 155-255.
Pyšek, P., Jarošík, V., Pergl, J., Randall, R., Chytrý, M., Kühn, I., ... Sádlo, J. (2009). The global invasion success of Central European plants is related to distribution characteristics in their native range and species traits. Diversity and Distributions, 3, 891-903. https://doi. org/10.1111/j.1472-4642.2009.00602.x

Pyšek, P., Manceur, A. M., Alba, C., McGregor, K. F., Pergl, J., Štajerová, K., ... Kühn, I. (2015). Naturalization of central European plants in North America: Species traits, habitats, propagule pressure, residence time. Ecology, 96, 762-774. https://doi. org/10.1890/14-1005.1

Pyšek, P., Pergl, J., Essl, F., Lenzner, B., Dawson, W., Kreft, H., ... van Kleunen, M. (2017). Naturalized alien flora of the world. Preslia, 89, 203-274. https://doi.org/10.23855/preslia.2017.203

Qian, H., \& Jin, Y. (2016). An updated megaphylogeny of plants, a tool for generating plant phylogenies and an analysis of phylogenetic community structure. Journal of Plant Ecology, 9, 233-239. https://doi. org/10.1093/jpe/rtv047

R Core Team. (2018). R: A language and environment for statistical computing. Vienna, Austria: R Foundation for Statistical Computing.

Razanajatovo, M., Maurel, N., Dawson, W., Essl, F., Kreft, H., Pergl, J., ... van Kleunen, M. (2016). Plants capable of selfing are more likely to become naturalized. Nature Communications, 7, 13313. https://doi. org/10.1038/NCOMMS13313

Reichard, S. H., \& White, P. (2001). Horticulture as a pathway of invasive plant introductions in the United States. BioScience, 51, 103-113. https://doi.org/10.1641/0006-3568

Rejmanek, M., \& Richardson, D. M. (1996). What attributes make some plant species more invasive? Ecology, 77, 1655-1661. https://doi. org/10.2307/2265768

Robinson, B. S., Inger, R., \& Gaston, K. J. (2017). Drivers of risk perceptions about the invasive non-native plant Japanese knotweed in domestic gardens. Biological Invasions, 19, 2927-2940. https://doi. org/10.1007/s10530-017-1495-0

Schielzeth, H. (2010). Simple means to improve the interpretability of regression coefficients. Methods in Ecology and Evolution, 1, 103-113. https://doi.org/10.1111/j.2041-210X.2010.00012.x

Seebens, H., Blackburn, T. M., Dyer, E. E., Genovesi, P., Hulme, P. E., Jeschke, J. M., ... Essl, F. (2017). No saturation in the accumulation of alien species worldwide. Nature Communications, 8, 14435. https:// doi.org/10.1038/ncomms14435

Seebens, H., Blackburn, T. M., Dyer, E. E., Genovesi, P., Hulme, P. E., Jeschke, J. M., ... Essl, F. (2018). Global rise in emerging alien species results from increased accessibility of new source pools. Proceedings of the National Academy of Sciences USA, 115, E2264-E2273. https:// doi.org/10.1073/pnas.1719429115

Sharrock, S. L. (2011). The biodiversity benefits of botanic gardens. Trends in Ecology and Evolution, 26, 433. https://doi.org/10.1016/j. tree.2011.05.008

Swinton, J.(2009). Venn diagramsin R with the Vennerablepackage. Retrieved from https://r-forge.r-project.org/scm/viewvc.php/*checkout*/pkg/ Vennerable/inst/doc/Venn.pdf?revision=58\&root=vennerable

van der Bijl, W. (2018). phylopath: Easy phylogenetic path analysis in R. PeerJ, 6, e4718. https://doi.org/10.7717/peerj.4718

van Kleunen, M., Dawson, W., Essl, F., Pergl, J., Winter, M., Weber, E., ... Pyšek, P. (2015). Global exchange and accumulation of non-native plants. Nature, 525, 100-103. https://doi.org/10.1038/nature14910

van Kleunen, M., Dawson, W., \& Maurel, N. (2015). Characteristics of successful alien plants. Molecular Ecology, 24, 1954-1968. https:// doi.org/10.1111/mec.13013

van Kleunen, M., Johnson, S. D., \& Fischer, M. (2007). Predicting naturalization of southern African Iridaceae in other regions. Journal of Applied Ecology, 44, 594-603. https://doi. org/10.1111/j.1365-2664.2007.01304.x

van Kleunen, M., Essl, F., Pergl, J., Brundu, G., Carboni, M., Dullinger, S., ... Dehnen-Schmutz, K. (2018). The changing role of ornamental 
horticulture in alien plant invasions. Biological Reviews, 93, 14211437. https://doi.org/10.1111/brv.12402

von Hardenberg, A., \& Gonzalez-Voyer, A. (2013). Disentangling evolutionary cause-effect relationships with phylogenetic confirmatory path analysis. Evolution, 67, 378-387. https://doi. org/10.1111/j.1558-5646.2012.01790.x

Wang, H., Harrison, S. P., Prentice, I. C., Yang, Y., Bai, F., Togashi, H. F., ... $\mathrm{Ni}$, J. (2018). The China Plant Trait Database: Toward a comprehensive regional compilation of functional traits for land plants. Ecology, 99, 500. https://doi.org/10.1002/ecy.2091

Webb, C. O., Ackerly, D. D., \& Kembel, S. W. (2008). Phylocom: Software for the analysis of phylogenetic community structure and trait evolution. Bioinformatics, 24, 2098-2100. https://doi.org/10.1093/ bioinformatics/btn358

Williamson, M., Dehnen-Schmutz, K., Kühn, I., Hill, M., Klotz, S., Milbau, A., ... Pyšek, P. (2009). The distribution of range sizes of native and alien plants in four European countries and the effects of residence time. Diversity and Distributions, 15, 158-166. https://doi. org/10.1111/j.1472-4642.2008.00528.x

Wright, I. J., Reich, P. B., Westoby, M., Ackerly, D. D., Baruch, Z., Bongers, F., ... Villar, R. (2004). The worldwide leaf economics spectrum. Nature, 428, 821-827. https://doi.org/10.1038/nature02403

Zanne, A. E., Tank, D. C., Cornwell, W. K., Eastman, J. M., Smith, S. A., FitzJohn, R. G., ... Beaulieu, J. M. (2014). Three keys to the radiation of angiosperms into freezing environments. Nature, 506, 89-92. https://doi.org/10.1038/nature12872

\section{BIOSKETCH}

WEN-YONG GUO is a postdoctoral ecologist interested in plant invasions and macroecology. His primary research focus is on the investigation of anthropogenic, environmental and ecological factors underlying naturalization and invasion success of alien plants. He also uses introduced plant species as model systems to investigate evolutionary questions. 